\title{
Produção e atributos de qualidade de cultivares de macieira nas condições subtropicais da região Leste paulista
}

\author{
Production and quality attributes of apple tree cultivars in subtropical conditions at eastern of São \\ Paulo state
}

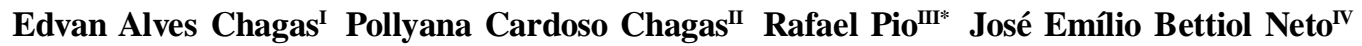 \\ Juliana Sanches ${ }^{\mathrm{V}}$ Silvia Antoniali do Carmo ${ }^{\mathrm{V}}$ Patrícia Cia $^{\mathrm{v}}$ Moacir Pasqual $^{\mathrm{II}}$ \\ Angélica dos Santos Carvalho ${ }^{\mathrm{II}}$
}

\section{RESUMO}

Objetivou-se avaliar o desempenho adaptativo, produtivo e atributos de qualidade de cultivares de macieira nas condições subtropicais da região leste paulista. Para tal, um ensaio de competição de cultivares foi implantado no município de Jundiaí, SP, com sete cultivares ('Eva', 'Condessa', 'Princesa', 'Rainha', 'Imperial Gala', 'Daiane', $e$ 'Baronesa'). O experimento foi implantado em 2006, no espaçamento de 3,0mx1,5m, com mudas enxertadas no portaenxerto Marubakaido e interenxerto M9. As avaliações foram realizadas em dois ciclos produtivos (2008/09 e 2009/10), analisando-se os aspectos fenológicos, produtivos e atributos de qualidade do fruto. As cultivares de macieira 'Eva', 'Baronesa' $e$ 'Princesa' apresentaram maior produção de frutos. A cultivar 'Baronesa' apresentou atributos de qualidade mais adequados ao consumo ao natural, com menor acidez titulável e boa firmeza de polpa e ratio mais elevado.

Palavras-chave: Malus domestica, inverno ameno, melhoramento, aspectos fenológicos.

\section{ABSTRACT}

These research aimed evaluate the production and quality attributes of apple tree cultivars in subtropical conditions at eastern of São Paulo state. For such, an assay of competition among cultivars was implanted in the Jundiai city, SP, with seven cultivars ('Eva', 'Condessa', 'Princesa', 'Rainha', 'Imperial Gala', 'Daiane', and 'Baronesa'). The experiment was implanted in 2006, the spacing was 3,0mx1,5m, and the plants were grafting in Marubakaido roostock and M9 intergrafting. The evaluations had been carried through in two production cycle (2008/09 and 2009/10), the phenological stage, productive aspects and fruit quality attributes were evaluated. 'Eva', 'Baronesa' and 'Princesa' showed higher productive performance. The 'Baronesa' apple presented fruit quality attributes most suitable for the fresh market, i.e., lower acidity and good firmness, and the highest ratio.

Key words: Malus domestica, low chilling, breeding, stage phenological.

\section{INTRODUÇÃO}

A adoção de cultivares de frutíferas de clima temperado, que necessitam de menor quantidade de unidades de frio, quando cultivadas em regiões de inverno ameno, possibilita a colheita dos frutos em épocas de menores ofertas (BARBOSA et al., 2010). Isso devido ao início da safra nessas regiões ocorrer em época antecipada, em relação às tradicionais regiões produtoras do Rio Grande do Sul e Santa Catarina (ARAÚJO et al., 2008). Essa precocidade de maturação é decorrente do clima hibernal mais quente, o que possibilita efetuar a poda e a indução da brotação das gemas com produtos químicos ainda no inverno, por não haver riscos de geadas tardias (BETTIOL NETO et al., 2011).

Em função do exposto, a fruticultura de clima temperado deixou de ser praticada somente na região Sul do país, deslocando-se para outras regiões,

IEmpresa Brasileira de Pesquisa Agropecuária (Embrapa Roraima), Boa Vista, RR, Brasil.

IUniversidade Federal de Roraima (EAGRO/UFRR), Campus Paricarana, Boa Vista, RR, Brasil.

IIIUniversidade Federal de Lavras (UFLA), 37200-000, Lavras, MG, Brasil. E-mail: rafaelpio@dag.ufla.br. *Autor para correspondência.

${ }^{\mathrm{I}}$ Centro de Frutas, Instituto Agronômico (IAC), Jundiaí, SP, Brasil.

${ }^{\text {v}}$ Centro de Engenharia e Automação, IAC, Jundiaí, SP, Brasil. 
a exemplo de São Paulo, Minas Gerais e Paraná. Oreflexo dessa migração ocasionou a implantação de inúmeros pomares dessas frutíferas em São Paulo e Minas Gerais (OLIVEIRA et al., 2011; OLIVEIRA et al., 2012).

Contribuição marcante para o avanço da pomicultura na região Sudeste ocorreu em 1999 com o lançamento da cultivar 'IAPAR 75 - Eva', macieira precoce com baixa necessidade de frio hibernal, adaptada para regiões de inverno ameno (HAUAGGE \& TSUNETA, 1999), destacando-se o Estado de Minas Gerais, onde houve expansão das áreas cultivadas para maçãs nos últimos cinco anos de 79ha, passando a deter 151 ha em cultivo (IBGE, 2011). No estado de São Paulo, o cultivo de maçã é incipiente, no entanto, em décadas passadas, possuía expressão comercial. Devido à carência de cultivares adaptadas às condições climáticas de São Paulo, a pomicultura deixou de ser expressiva. Assim, há necessidade de selecionar-se cultivares de baixa necessidade de frio para as condições paulistas, principalmente no Leste do Estado (BETTIOL NETO et al., 2011). Além do mais, é necessário ter outras opções de cultivares além da 'Eva', devido à necessidade de se alocar plantas polinizadores nos pomares de maçã (PETRI et al., 2011).

O presente trabalho teve como objetivo avaliar o desempenho produtivo e atributos de qualidade de cultivares de macieira nas condições subtropicais da região Leste paulista.

\section{MATERIAL E MÉTODOS}

O experimento foi realizado no município de Jundiaí, SP, localizado a $23^{\circ} 08^{\prime}$ de latitude sul e $46^{\circ} 55^{\prime}$ de longitude oeste com altitude média de $700 \mathrm{~m}$. O clima da região é classificado como mesotérmico de inverno seco (Cwa), comumente chamado de tropical de altitude, apresentando temperatura anual média de $21,4^{\circ} \mathrm{C}$ (média mínima: $15,3^{\circ} \mathrm{C}$; média máxima: $27,4^{\circ} \mathrm{C}$ ), precipitação média anual de $1.400 \mathrm{~mm}$ e menos de $40 \mathrm{~h}$ de acúmulo de unidades de frio. O solo é classificado como Latossolo Vermelho-Amarelo Distrófico típico, A moderado, textura argilosa.

As covas foram preparadas 30 dias antes do plantio na dimensão de 40x40x40cm e adubadas com $10 \mathrm{~kg}$ de esterco bovino curtido, $800 \mathrm{~g}$ de Yorim e $300 \mathrm{~g}$ de KCl. Plantas de sete cultivares de maçã ('Eva', 'Condessa', 'Princesa', 'Rainha', 'Imperial Gala', 'Daiane' e 'Baronesa') foram implantadas em setembro de 2006, no espaçamento de 3,0mx1,5m (2.222 plantas $\left.\mathrm{ha}^{-1}\right)$. As mudas enxertadas em porta-enxerto Marubakaido e interenxerto M9 foram adquiridas no viveiro Clone ${ }^{\circledR}$, Curitiba, PR, na forma de raiz nua. Após o plantio, as plantas foram conduzidas no suporte tipo "espaldeira" em sistema de líder central modificado. O experimento foi instalado no delineamento em blocos casualizados e os tratamentos foram constituídos pelas cultivares, contendo quatro blocos e cinco plantas por unidade experimental, sendo avaliadas somente as três centrais.

Após o plantio, o solo foi manejado deixando-se a cobertura permanente nas entrelinhas e a linha de plantio completamente limpa, através da utilização de capinas manuais de coroamento e uso de herbicida. A adubação foi realizada segundo a análise de solo e o controle das pragas e doenças foi realizado com a utilização, quando necessária, de fungicidas e inseticidas recomendados para a macieira.

A indução vegetativa e floral foi realizada no dia 20 de julho de 2008 e 2009 , quando as plantas ainda apresentavam gemas dormentes. Utilizou-se cianamida hidrogenada na concentração de $3 \%$ do produto comercial Dormex ${ }^{\circledR}$, acrescido de $1 \%$ de óleo mineral. Para a aplicação, utilizou-se um pulverizador manual de 20L, aplicando volume de calda correspondente a 600L de calda por hectare. A poda de frutificação foi realizada três dias após o tratamento para a indução da brotação das gemas.

Durante as safras 2008/09 e 2009/10, registraram-se as fenofases (início, término e duração da florada e colheita das cultivares de macieira), número médio de frutos, produção média e produtividade estimada. Quatro amostras homogêneas contendo dez frutos de cada cultivar foram separadas durante a colheita, para a mensuração da massa, diâmetro e comprimento médio dos frutos. Os atributos de qualidade foram apenas avaliados no segundo ciclo produtivo (2009/10).

De cada cultivar, foram colhidas quatro amostras contendo oito frutos e avaliadas quanto a: coloração da epiderme e da polpa, tomadas pela leitura do colorímetro Hunter, sistema CIELab dos parâmetros de Luminosidade $\left(\mathrm{L}^{*}\right)$, cor verde $\left(-\mathrm{a}^{*}\right)$, cor vermelha $\left(+a^{*}\right)$, cor amarela $\left(+b^{*}\right)$, com duas leituras para cor da epiderme e da polpa, sendo os resultados expressos em luminosidade [em valores de 0 (preto) a 100 (branco)] e ângulo de cor ou Hue ( $\arctan \left(\mathrm{b}^{*} / \mathrm{a}^{*}\right)$; firmeza da polpa, através de penetrômetro manual Effegi, equipado com ponteira de $8 \mathrm{~mm}$, tomada pela leitura na região equatorial, após a retirada da epiderme; acidez total titulável, por titulometria com solução de hidróxido de sódio $(0,5 \mathrm{~N})$, expresso em gramas de ácido málico por $100 \mathrm{~g}$ de polpa; sólidos solúveis totais, determinado em refratômetro digital, sendo os valores expressos em \%; ratio, obtido pela relação entre o teor de sólidos solúveis totais e a acidez total titulável. Os dados foram submetidos à análise de variância e as médias 
comparadas pelo teste Scott-Knott, a 5\% de probabilidade de erro.

\section{RESULTADOS E DISCUSSÃO}

Verificou-se, para todas as cultivares de macieira avaliadas nos ciclos produtivos 2008/09 e 2009/ 10 , que o início do florescimento ocorreu na segunda quinzena do mês de agosto (Tabela 1). Com relação a duração do florescimento, observou-se que a cultivar Princesa permaneceu maior tempo em floração, em ambos os ciclos de avaliação. Outro aspecto importante notado no presente trabalho foi a coincidência do período de florescimento entre algumas cultivares, pois, segundo PETRI et al. (2011), a macieira apresenta alto grau de incompatibilidade, necessitando de um esquema especial de cultivo com duas ou mais cultivares que permita a polinização cruzada. Nas condições testadas, as cultivares 'Eva', 'Princesa' e 'Imperial Gala' apresentaram coincidência no período de florescimento, podendo uma servir de polinizadora para a outra.

A colheita das cultivares concentrou-se entre os meses de janeiro e fevereiro, no ciclo produtivo 2008/09, e dezembro a fevereiro, no ciclo produtivo 2009/ 10. A duração da colheita foi menor no primeiro ciclo produtivo, quando comparada com o segundo. Outro fato relevante foi o significativo aumento no período de duração de colheita das cultivares 'Eva', 'Condessa', 'Princesa' e 'Baronesa' no segundo ciclo produtivo (Tabela 1). A diferença quanto ao período de colheita entre os dois anos de avaliação pode estar relacionada às condições climáticas do local.

No Brasil, a colheita de maçãs nas regiões tradicionais de cultivo dos Estados de Santa Catarina e Rio Grande do Sul inicia-se no final do mês de fevereiro e termina no início do mês de maio (PETRI et al., 2011). Nas condições em que o presente trabalho foi realizado, verificou-se que o início de colheita pode ser antecipado para novembro, obtendo-se colheitas mais precoces. Contudo, para se obter êxito nesse sentido é necessário pesquisar sobre o uso de indutores de brotação em diferentes épocas do ano e em diferentes concentrações.

Com relação à altura das plantas e ao diâmetro da copa, a cultivar 'Rainha' se destacou no ciclo produtivo 2008/09. Já no ciclo produtivo 2009/10, as cultivares apresentaram comportamento muito semelhante entre si quanto a esse aspecto, excetuando-se as cultivares 'Princesa' e 'Condessa', que apresentaram menor altura e diâmetro de copa (Tabela 2).

Excelente desempenho produtivo foi constatado dentre as diversas cultivares testadas. Com relação ao número médio de frutos por planta no ciclo produtivo 2008/09, 'Eva', 'Rainha', 'Condessa', 'Princesa' e 'Baronesa' foram as que apresentaram maior produção de frutos (Tabela 2). Maior evidencia na produção foi constatada no ciclo produtivo 2009/ 10, quando a cultivar 'Eva' manteve excelente produção de frutos (156), juntamente com a 'Baronesa' (138). No ciclo produtivo 2009/10, também foi possível constatar que os menores números de frutos foram produzidos pela 'Imperial Gala' (oito). Tendência semelhante foi observada na produção em $\mathrm{kg}_{\text {planta }}{ }^{-1}$. As cultivares 'Eva' e 'Baronesa' novamente se destacaram entre as demais no segundo ciclo de avaliação, mas devido à elevada massa média dos frutos da cultivar 'Princesa', esta também se destacou na produção (Tabela 2). Quando se analisou a produtividade estimada das diferentes cultivares, constatou-se que houve elevada influência da massa, comprimento e diâmetro médio dos frutos produzidos pelas respectivas cultivares na

Tabela 1 - Descrição fenológica - início (I), término (T) e duração da florada e colheita (D) de cultivares de macieira em Jundiaí-SP, nos ciclos produtivos 2008/09 e 2009/10.

\begin{tabular}{|c|c|c|c|c|c|c|c|c|c|c|c|c|}
\hline \multirow{3}{*}{ Cultivares de macieira } & \multicolumn{6}{|c|}{----------------Ciclo produtivo 2008/09--------------- } & \multicolumn{6}{|c|}{----------------Ciclo produtivo 2009/10---------------- } \\
\hline & \multicolumn{3}{|c|}{ Floração } & \multicolumn{3}{|c|}{ colheita } & \multicolumn{3}{|c|}{ Floração } & \multicolumn{3}{|c|}{ Colheita } \\
\hline & I & $\mathrm{T}$ & $\begin{array}{c}\mathrm{D} \\
\text { (dias) }\end{array}$ & I & $\mathrm{T}$ & $\begin{array}{c}\mathrm{D} \\
\text { (dias) }\end{array}$ & I & $\mathrm{T}$ & $\begin{array}{c}\mathrm{D} \\
\text { (dias) }\end{array}$ & I & $\mathrm{T}$ & $\begin{array}{c}\mathrm{D} \\
\text { (dias) }\end{array}$ \\
\hline 'Eva' & $20 / 08$ & $10 / 09$ & 21 & $08 / 01$ & $15 / 01$ & 7 & $08 / 08$ & $01 / 09$ & 24 & $05 / 12$ & $21 / 01$ & 47 \\
\hline 'Condessa' & $20 / 08$ & $19 / 09$ & 22 & $05 / 01$ & $21 / 01$ & 16 & $18 / 08$ & $10 / 09$ & 23 & $01 / 12$ & $15 / 01$ & 45 \\
\hline 'Princesa' & $20 / 08$ & $19 / 09$ & 30 & $12 / 01$ & $27 / 01$ & 15 & 05/08 & 07/09 & 33 & $18 / 12$ & $21 / 01$ & 34 \\
\hline 'Rainha' & $27 / 08$ & $19 / 09$ & 23 & $22 / 01$ & $08 / 02$ & 17 & $18 / 08$ & $13 / 09$ & 26 & $28 / 12$ & $15 / 01$ & 18 \\
\hline 'Imperial Gala' & $28 / 08$ & $19 / 09$ & 22 & $08 / 02$ & $15 / 02$ & 7 & $23 / 08$ & $12 / 09$ & 20 & $01 / 02$ & $11 / 02$ & 10 \\
\hline 'Daiane' & $24 / 08$ & $15 / 09$ & 22 & $18 / 01$ & $18 / 02$ & 31 & $18 / 08$ & 07/09 & 20 & $20 / 12$ & $21 / 01$ & 32 \\
\hline 'Baronesa' & $24 / 08$ & $15 / 09$ & 22 & $28 / 01$ & $20 / 02$ & 23 & $10 / 08$ & 07/09 & 28 & $29 / 12$ & $17 / 02$ & 50 \\
\hline
\end{tabular}


Tabela 2 - Altura das plantas (m), diâmetro da copa $(\mathrm{m}), \mathrm{n}^{\circ}$ de ramos por líder central, número médio de frutos, produção média (kg planta ${ }^{-1}$ ) e produtividade estimada ( $\mathrm{kg}$ planta $\left.^{-1}\right)$, espaçamento $3 \times 1,5 \mathrm{~m}$, considerando uma densidade populacional de 2.222 plantas por ha), massa média dos frutos $(\mathrm{g})$, diâmetro médio dos frutos $(\mathrm{mm})$ e comprimento médio dos frutos (mm) de cultivares de macieira em Jundiaí-SP, nos ciclos produtivos 2008/09 e 2009/10.

\begin{tabular}{|c|c|c|c|c|c|c|}
\hline \multirow[t]{2}{*}{ Cultivares de macieira } & $2008 / 09$ & $2009 / 10$ & $2008 / 09$ & $2009 / 10$ & $2008 / 09$ & $2009 / 10$ \\
\hline & \multicolumn{2}{|c|}{-------Altura das plantas (m)------- } & \multicolumn{2}{|c|}{-------Diâmetro da copa (m) ------- } & \multicolumn{2}{|c|}{-------No de ramos/líder central------- } \\
\hline 'Eva' & $2,35 \mathrm{~b}$ & $2,61 \mathrm{a}$ & 1,69 a & $2,07 \mathrm{a}$ & $13,50 \mathrm{a}$ & 89,25 a \\
\hline 'Condessa' & $2,02 \mathrm{c}$ & $2,18 \mathrm{~b}$ & $1,37 \mathrm{~b}$ & $1,70 \mathrm{~b}$ & $11,37 \mathrm{a}$ & $37,25 \mathrm{~b}$ \\
\hline 'Princesa' & $1,74 \mathrm{c}$ & $1,91 \mathrm{~b}$ & $1,21 \mathrm{~b}$ & $1,68 \mathrm{~b}$ & 13,37 a & 60,25 a \\
\hline 'Rainha' & $2,63 \mathrm{a}$ & 3,02 a & $1,70 \mathrm{a}$ & $2,22 \mathrm{a}$ & $10,25 \mathrm{a}$ & $30,87 \mathrm{~b}$ \\
\hline 'Imperial Gala' & $2,24 \mathrm{~b}$ & 2,72 a & $1,40 \mathrm{~b}$ & 1,96 a & $6,75 \mathrm{~b}$ & $29,12 \mathrm{~b}$ \\
\hline 'Daiane' & $1,95 \mathrm{c}$ & $2,07 \mathrm{a}$ & $1,38 \mathrm{~b}$ & $1,85 \mathrm{a}$ & $7,87 \mathrm{~b}$ & $40,50 \mathrm{~b}$ \\
\hline 'Baronesa' & $2,25 \mathrm{~b}$ & $2,56 \mathrm{a}$ & $1,39 \mathrm{~b}$ & 2,16 a & 11,87 a & 61,62 a \\
\hline \multirow[t]{2}{*}{$\mathrm{CV}(\%)$} & 14,23 & 14,60 & 20,06 & 16,92 & 26,79 & 25,50 \\
\hline & \multicolumn{2}{|c|}{ - } & \multicolumn{2}{|c|}{------Produção (kg planta $\left.{ }^{-1}\right)------$} & \multicolumn{2}{|c|}{ Produtividade estimada ( $k g$ planta $\left.{ }^{-1}\right)$} \\
\hline 'Eva' & 36,9 a & 156,7 a & $4,5 \mathrm{a}$ & $14,1 \mathrm{a}$ & $10,0 \mathrm{a}$ & $31,3 \mathrm{a}$ \\
\hline 'Condessa' & 23,8 a & $52,8 \mathrm{c}$ & $2,8 \mathrm{a}$ & $6,0 \mathrm{~b}$ & 6,3 a & $13,4 \mathrm{~b}$ \\
\hline 'Princesa' & $23,0 \mathrm{a}$ & $95,7 \mathrm{~b}$ & $3,4 \mathrm{a}$ & 13,2 a & $7,7 \mathrm{a}$ & 29,3 a \\
\hline 'Rainha' & 28,1 a & $73,2 \mathrm{c}$ & 4,5 a & $9,3 \mathrm{~b}$ & 10,0 a & $20,6 \mathrm{~b}$ \\
\hline 'Imperial Gala' & $7,1 \mathrm{~b}$ & $8,2 \mathrm{~d}$ & $0,8 \mathrm{~b}$ & $0,8 \mathrm{c}$ & $1,9 \mathrm{~b}$ & $1,8 \mathrm{c}$ \\
\hline 'Daiane' & $16,9 \mathrm{~b}$ & $51,6 \mathrm{c}$ & $2,2 \mathrm{~b}$ & $6,9 \mathrm{~b}$ & $4,9 \mathrm{~b}$ & $15,4 \mathrm{~b}$ \\
\hline 'Baronesa' & 19,2 a & $138,1 \mathrm{a}$ & $2,3 \mathrm{~b}$ & $17,5 \mathrm{a}$ & $5,0 \mathrm{~b}$ & 38,9 a \\
\hline \multirow[t]{2}{*}{$\mathrm{CV}(\%)$} & 29,1 & 20,8 & 23,4 & 22,4 & 23,4 & 22,4 \\
\hline & \multicolumn{2}{|c|}{----Massa média dos frutos (g) ---- } & \multicolumn{2}{|c|}{ Diâmetro médio dos frutos (mm) } & \multicolumn{2}{|c|}{$\begin{array}{l}\text { Comprimento médio dos frutos } \\
\text { (mm) }\end{array}$} \\
\hline 'Eva' & $119,2 \mathrm{~b}$ & $87,5 \mathrm{~b}$ & $61,7 \mathrm{~b}$ & $56,1 \mathrm{~b}$ & $59,5 \mathrm{c}$ & $53,3 \mathrm{c}$ \\
\hline 'Condessa' & $127,1 \mathrm{~b}$ & 113,9 a & $63,2 \mathrm{~b}$ & 61,6 a & $63,9 \mathrm{~b}$ & $63,3 \mathrm{~b}$ \\
\hline 'Princesa' & 145,9 a & $141,4 \mathrm{a}$ & 67,9 a & $66,8 \mathrm{a}$ & $60,5 \mathrm{c}$ & $60,8 \mathrm{~b}$ \\
\hline 'Rainha' & 160,3 a & 126,3 a & 70,6 a & 65,9 a & 67,7 a & $61,9 \mathrm{~b}$ \\
\hline 'Imperial Gala' & $108,6 \mathrm{~b}$ & 96,6 b & $59,8 \mathrm{~b}$ & $59,8 \mathrm{~b}$ & $56,3 \mathrm{c}$ & $55,3 \mathrm{c}$ \\
\hline 'Daiane' & $125,2 \mathrm{~b}$ & $134,4 \mathrm{a}$ & $62,6 \mathrm{~b}$ & 63,2 a & $65,3 \mathrm{~b}$ & 67,3 a \\
\hline 'Baronesa' & $116,8 \mathrm{~b}$ & 128,8 a & 68,8 a & $64,5 \mathrm{a}$ & $66,0 \mathrm{a}$ & $60,5 \mathrm{~b}$ \\
\hline $\mathrm{CV}(\%)$ & 13,7 & 8,8 & 5,7 & 4,0 & 5,7 & 4,7 \\
\hline
\end{tabular}

*Médias não seguidas pela mesma letra na coluna diferem entre si pelo teste Scott-Knott, a 5\% de probabilidade de erro.

produtividade estimada em ambos os ciclos avaliados. Ainda se observou um aumento considerável do ciclo 2008/09 para 2009/10, com destaque para as macieiras 'Eva', 'Princesa' e 'Baronesa', que produziram mais de $31 \mathrm{t} \mathrm{ha}^{-1}$ (Tabela 2). Percebe-se que essas três cultivares também foram as que emitiram maior número de ramos do líder central no segundo ciclo de avaliação. Por esses resultados, percebe-se que essas três cultivares ('Eva', 'Princesa' e 'Baronesa') apresentaram melhor adaptação às condições climáticas do Leste paulista, frente a boa brotação das plantas e produção de frutos. Por outro lado, 'Imperial Gala' apresentou menor produtividade $\left(1,8 \mathrm{tha}^{-1}\right)$, demonstrando falta de adaptação às condições climáticas do local onde foi realizado o experimento (Tabela 2 ).
A exceção da 'Eva' e 'Imperial Gala', as demais cultivares apresentaram frutos de bom calibre (massa) no segundo ciclo de avaliação, concordando com SANTOS et al. (2007), que obtiveram frutos com massa superior a 100g. Constatou-se, de modo geral, que a massa, diâmetro e comprimento médios dos frutos foram maiores no ciclo 2008/09, quando comparado com o ciclo 2009/10 (Tabela 2). Essa constatação é devida ao fato de as plantas terem produzidos menor volume de frutos no primeiro ciclo e, consequentemente, os frutos tiveram melhor qualidade com relação às dimensões. Por outro lado, se compararmos o número de frutos produzidos pelas diversas cultivares no ciclo 2009/10 e suas variáveis de qualidade, constata-se que a massa, diâmetro e comprimento médios dos frutos 
foram menores. A cultivar 'Eva' foi a que apresentou maior número de frutos no ciclo 2009/10, porém, menor massa média de frutos. Já a cultivar 'Baronesa' apresentou elevado número de frutos por planta e também boa massa média de seus frutos, no segundo ciclo de avaliação (Tabela 2). Isso demonstra que essa cultivar pode ser uma opção para regiões de inverno ameno, não necessariamente devendo-se sóutilizar a 'Eva' .

Com relação aos atributos de qualidade, verificou-se grande variação da coloração da epiderme dos frutos, constatando diferença significativa entre as cultivares (Tabela 3). Segundo IGLESIAS et al. (2008), a coloração da epiderme de maçãs não é considerada um índice de maturação, pois se desenvolve precocemente e varia grandemente em função de fatores ambientais e das cultivares. A cultivar 'Imperial Gala' apresentou a coloração da epiderme mais vermelha (menor ângulo Hue) e mais escura (menor luminosidade), seguidas pelas cultivares 'Condessa', 'Eva' e 'Princesa'. As macieiras 'Gala' e suas variações ('Brookfield Gala', 'Buckeye Gala' e 'Ruby Gala') iniciam a mudança da coloração da epiderme de seus frutos em estágios iniciais de desenvolvimento ou em condições ambientais associadas com temperaturas elevadas ou com pouca incidência de luz (partes sombreadas da copa das plantas) (IGLESIAS et al., 2008).

Em relação à coloração da polpa, notou-se, através do ângulo Hue, que as cultivares apresentaram diferentes intensidades da cor amarela, apresentando diferença significativa entre elas (Tabela 3). A cultivar 'Baronesa' se destacou como a que apresentou a cor da polpa amarela mais pálida. Segundo DROGOUDI et al. (2008), a coloração da epiderme não está correlacionada com a cor da polpa, sugerindo que a cor externa não interfere na interna.

A composição química de maçãs pode variar dependendo da cultivar, região de produção e práticas culturais (WU et al., 2007). No presente trabalho, as cultivares estudadas apresentaram diferenças significativas em relação aos parâmetros físicoquímicos estudados (Tabela 3). Quanto à firmeza, verificou-se que as maçãs 'Eva', 'Princesa', 'Daiane' e 'Baronesa' foram as que se mostraram com polpa mais firme, enquanto que a 'Rainha' foi a mais macia. Em relação à acidez titulável, as cultivares 'Rainha' e 'Eva' foram as mais ácidas $\left(0,61 \mathrm{~g} 100 \mathrm{~g}^{-1}\right.$ e $0,63 \mathrm{~g} 100 \mathrm{~g}^{-1}$, respectivamente) e a 'Condessa', 'Baronesa' e 'Imperial

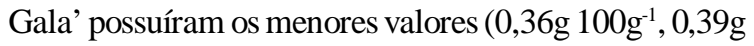

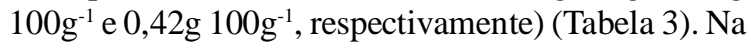
região Sul do Brasil, os teores de acidez titulável encontrados na literatura variaram de $0,20 \mathrm{~g} 100 \mathrm{~g}^{-1} \mathrm{a}$

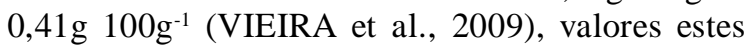
inferiores aos encontrados no presente trabalho para a maioria das cultivares (Tabela 3). A alta acidez apresenta-se como um atributo de grande expressão na discriminação de cultivares de maçã, sendo

Tabela 3 - Luminosidade e ângulo de cor ou Hue da epiderme e polpa, firmeza, acidez titulável (AT), sólidos solúveis (SS) e ratio (relação SST/AT) de cultivares de macieira em Jundiaí-SP.

\begin{tabular}{|c|c|c|c|c|}
\hline \multirow{2}{*}{ Cultivares de macieira } & \multicolumn{2}{|c|}{ 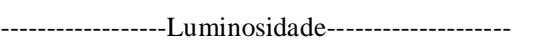 } & \multicolumn{2}{|c|}{ 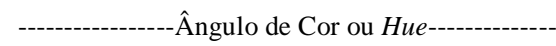 } \\
\hline & Epiderme & Polpa & Epiderme & Polpa \\
\hline 'Eva' & $45,2 \mathrm{~b}$ & $85,2 \mathrm{~b}$ & $37,7 \mathrm{c}$ & $83,7 \mathrm{c}$ \\
\hline 'Condessa' & $44,4 \mathrm{~b}$ & $85,7 \mathrm{~b}$ & $34,2 \mathrm{c}$ & $84,6 \mathrm{c}$ \\
\hline 'Princesa' & $46,4 \mathrm{~b}$ & 86,9 a & $42,7 \mathrm{c}$ & $95,5 \mathrm{~b}$ \\
\hline 'Rainha' & $54,3 \mathrm{a}$ & $83,6 \mathrm{c}$ & $67,2 \mathrm{a}$ & $95,2 \mathrm{~b}$ \\
\hline 'Imperial Gala' & $39,3 \mathrm{c}$ & $83,5 \mathrm{c}$ & $28,6 \mathrm{c}$ & $85,3 \mathrm{c}$ \\
\hline 'Daiane' & 54,6 a & 86,5 a & $53,7 \mathrm{~b}$ & $93,2 \mathrm{~b}$ \\
\hline 'Baronesa' & $54,9 \mathrm{a}$ & $87,0 \mathrm{a}$ & $73,2 \mathrm{a}$ & $99,2 \mathrm{a}$ \\
\hline \multirow[t]{2}{*}{$\mathrm{CV}(\%)$} & 10,9 & 1,1 & 22,3 & 4,6 \\
\hline & Firmeza (N) & $\begin{array}{c}\text { AT } \\
\left(\mathrm{g} \text { de ác. málico } 100 \mathrm{~g}^{-1}\right)\end{array}$ & $\operatorname{SST}(\%)$ & Ratio (SST/AT) \\
\hline 'Eva' & $51,7 \mathrm{a}$ & $0,6 \mathrm{a}$ & $15,2 \mathrm{a}$ & $24,3 \mathrm{c}$ \\
\hline 'Condessa' & $44,6 \mathrm{~b}$ & $0,3 \mathrm{~d}$ & $13,3 \mathrm{~b}$ & $38,2 \mathrm{a}$ \\
\hline 'Princesa' & $53,9 \mathrm{a}$ & $0,5 \mathrm{~b}$ & $12,2 \mathrm{c}$ & $23,8 \mathrm{c}$ \\
\hline 'Rainha' & $39,6 \mathrm{c}$ & $0,6 \mathrm{a}$ & $12,0 \mathrm{c}$ & $19,9 \mathrm{~d}$ \\
\hline 'Imperial Gala' & $45,4 \mathrm{~b}$ & $0,4 \mathrm{~d}$ & $13,2 \mathrm{~b}$ & $31,8 \mathrm{~b}$ \\
\hline 'Daiane' & $52,2 \mathrm{a}$ & $0,5 \mathrm{c}$ & $12,9 \mathrm{~b}$ & $27,6 \mathrm{c}$ \\
\hline 'Baronesa' & $55,3 \mathrm{a}$ & $0,4 \mathrm{~d}$ & $11,9 \mathrm{c}$ & $30,6 \mathrm{~b}$ \\
\hline $\mathrm{CV}(\%)$ & 8,0 & 11,7 & 7,7 & 14,6 \\
\hline
\end{tabular}

*Médias não seguidas pela mesma letra na coluna diferem entre si pelo teste Scott-Knott, a 5\% de probabilidade de erro. 
importante para o mercado industrial de sucos. Com exceção das cultivares 'Condessa', 'Baronesa' e 'Imperial Gala', os valores encontrados para as demais maçãs estudadas encontram-se acima de $0,45{\mathrm{~g} 100 \mathrm{~g}^{-1}}^{-1}$ preconizado na literatura como limite entre as maçãs doces e as ácidas.

Os sólidos solúveis totais variaram de 15,22\% ('Eva') a 11,94\% ('Baronesa') (Tabela 3). Valores semelhantes foram encontrados em maçãs cultivadas no Sul do Brasil (VIEIRA et al., 2009). Os teores de açúcares em maçãs apresentam impacto bastante importante na aceitação pelo consumidor, e podem variar dependendo da cultivar e da posição do fruto na árvore: frutos expostos ao sol tendem a apresentar maiores teores de açúcar que os localizados nas partes sombreadas das árvores (FELICIANO et al., 2010). O ratio é responsável pelo sabor e aroma de maçãs (WU et al., 2007), já que as cultivares de maçãs com ratio inferior a 20 são mais adequadas para o processamento industrial (sucos e cidras), enquanto que as superiores a este valor são consideradas doces e aptas para o consumo in natura. Como se pode observar na tabela 3 , todas as cultivares estudadas apresentaram valores superiores a 20 , sendo classificadas como cultivares doces, com destaque para as cultivares 'Condessa', 'Imperial Gala' e 'Baronesa'. Resultados semelhantes foram encontrados em maçãs do Sul do Brasil (VIEIRA et al., 2009). Vale ressaltar que, apesar das cultivares 'Eva', 'Princesa', 'Rainha' e 'Daiane' apresentarem teores de acidez titulável acima de $0,45 \mathrm{~g} 100 \mathrm{~g}^{-1}$, o conteúdo de sólidos solúveis encontrado nessas cultivares foi suficientemente alto para elas apresentarem o ratio próximo ou acima de 20.

\section{CONCLUSÃO}

A colheita de maçãs de diferentes cultivares nas condições subtropicais da região Leste Paulista ocorre nos meses de janeiro e fevereiro no ciclo produtivo 2008/09 e dezembro a fevereiro no segundo ciclo produtivo.

As cultivares de macieira 'Eva', 'Baronesa' e 'Princesa' apresentam melhor desempenho produtivo nas condições subtropicais da região Leste paulista. Dessas, a 'Baronesa' produziu frutos de boa coloração, firmes, com baixa acidez e bom ratio.

\section{REFERÊNCIAS}

ARAÚJO, J.P.C. et al. Influência da poda de renovação e controle da ferrugem nas reservas de carboidratos e produção de pessegueiro precoce. Revista Brasileira de Fruticultura, v.30, n.2, p.331-335, 2008. Disponível em: <http:// www.scielo.br/scielo.php?script=sci_arttext\&pid=S0100-
$29452008000200011 \& \operatorname{lng}=\mathrm{pt} \& \mathrm{nrm}=\mathrm{iso} \& \mathrm{t} \operatorname{lng}=\mathrm{pt}>$. Acesso em: 30 mar. 2012. doi: dx.doi.org/10.1590/S010029452008000200011.

BARBOSA, W. et al. Advances in low-chilling peach breeding at Instituto Agronômico, São Paulo State, Brazil. Acta Horticulturae, v.872, p.147-150, 2010.

BETTIOL NETO, J.E. et al. Produção e atributos de qualidade de cultivares de marmeleiro na região Leste paulista. Revista Brasileira de Fruticultura, v.33, n.3, p.1035-1042, 2011. Disponível em: <http://www.scielo.br/scielo.php?script=sci_arttext\&pid=S0100$29452011000300042 \& \operatorname{lng}=$ pt\&nrm=iso\&tlng=en>. Acesso em: 30 mar. 2012. doi: 10.1590/S0100-29452011000300042.

DROGOUDI, P.D. et al. Peel and flesh antioxidant content and harvest quality characteristics of seven apple cultivars. Scientia Horticulturae, v.115, n.2, p.149-153, 2008.

FELICIANO, R.P et al. Characterization of traditional and exotic apple varieties from Portugal. Part 1: nutritional, phytochemical and sensory evaluation. Journal of Functional Foods, v.2, n.1, p.35-45, 2010.

HAUAGGE, R.; TSUNETA, M. 'IAPAR 75 - Eva', 'IAPAR 76 - Anabela' e 'IAPAR 77 - Carícia' - Novas cultivares de macieira com baixa necessidade em frio. Revista Brasileira de Fruticultura, v.21, n.3, p.239-242, 1999.

IGLESIAS, I. et al. Differences in fruit colour development, anthocyanin content, fruit quality and consumer acceptability of eight 'Gala' apple strains. Scientia Horticulturae, v.119, n.1, p.32-40, 2008.

INSTITUTO BRASILEIRO DE GEOGRAFIA E ESTATÍSTICA - IBGE. Produção agrícola municipal. Disponível em: <http://www.ibge.gov.br>. Acesso em: 12 dez. 2011.

OLIVEIRA, M.C. et al. Seleção de ameixeiras promissoras para a Serra da Mantiqueira. Revista Ceres, v.58, n.4, p.531-535, 2011. Disponível em: <http://www.scielo.br/scielo.php?script=sci_arttext\&pid=S0034$737 X 2011000400019 \& \operatorname{lng}=p t \& n r m=i s o \& t \operatorname{lng}=p t>$. Acesso em: 11 dez. 2011. doi: dx.doi.org/10.1590/S0034-737X2011000400019.

OLIVEIRA, M.C. et al. Características fenológicas e físicas e perfil de ácidos graxos em oliveiras no sul de Minas Gerais. Pesquisa Agropecuária Brasileira, v.47, n.1, p.30-35, 2011. Disponível em: <http://www.scielo.br/scielo.php?script=sci_arttext\&pid=S0100$204 X 2012000100005 \& \operatorname{lng}=p t \& n r m=i s o \& t \operatorname{lng}=p t>$. Acesso em: 30 mar. 2012. doi: dx.doi.org/10.1590/S0100-204X2012000100005.

PETRI, J.L. et al. Avanços na cultura da macieira no Brasil. Revista Brasileira de Fruticultura, v.33, n. especial, p.48-56, 2011. Disponível em: <http://www.scielo.br/scielo.php?script=sci_arttext\&pid=S0100$29452011000500007 \& \operatorname{lng}=$ pt\&nrm=iso $>$. Acesso em: $11 \mathrm{dez} .2011$. doi: dx.doi.org/10.1590/S0100-29452011000500007.

SANTOS, J.P. Qualidade de frutos ensacados em diferentes genótipos de macieira. Ciência Rural, v.37, n.6, p.1614-1620, 2007. Disponível em: <http://www.scielo.br/scielo.php?script=sci_arttext\&pid=S0103$84782007000600017 \& \operatorname{lng}=$ pt\&nrm=iso $>$. Acesso em: $11 \mathrm{dez} .2011$. doi: dx.doi.org/10.1590/S0103-84782007000600017.

VIEIRA, F.G.K. et al. Physico-chemical and antioxidant properties of six apple cultivars (Malus domestica Borkh) grown in southern Brazil. Scientia Horticulturae, v.122, n.3, p.421$425,2009$.

WU, J. et al. Chemical compositional characterization of some apple cultivars. Food Chemistry, v.103, n.1, p.88-93, 2007. 